\title{
Somatic neurofibromatosis type 1 (NF1) inactivation events in cutaneous neurofibromas of a single NF1 patient
}

\author{
Denise Emmerich $^{1,2}$, Tomasz Zemojtel ${ }^{2,3,4}$, Jochen Hecht ${ }^{1,5}$, Peter Krawitz ${ }^{1}$, Malte Spielmann ${ }^{1}$, \\ Jirko Kühnisch ${ }^{1,2}$, Karolina Kobus ${ }^{1}$, Monika Osswald ${ }^{1}$, Verena Heinrich ${ }^{2}$, Peter Berlien ${ }^{6}$, Ute Müller ${ }^{6}$, \\ Victor-F Mautner ${ }^{7}$, Katharina Wimmer ${ }^{8}$, Peter N Robinson ${ }^{2}$, Martin Vingron $^{3}$, Sigrid Tinschert ${ }^{8,9}$, \\ Stefan Mundlos ${ }^{1,2,5}$ and Mateusz Kolanczyk ${ }^{\star, 1,2}$
}

Neurofibromatosis type 1 (NF1) (MIM\#162200) is a relatively frequent genetic condition that predisposes to tumor formation. The main types of tumors occurring in NF1 patients are cutaneous and subcutaneous neurofibromas, plexiform neurofibromas, optic pathway gliomas, and malignant peripheral nerve sheath tumors. To search for somatic mutations in cutaneous (dermal) neurofibromas, whole-exome sequencing (WES) was performed on seven spatially separated tumors and two reference tissues (blood and unaffected skin) from a single NF1 patient. Validation of WES findings was done using routine Sanger sequencing or Sequenom IPlex SNP genotyping. Exome sequencing confirmed the existence of a known familial splice-site mutation NM_000267.3:c.3113+1G > A in exon 23 of NF1 gene (HGMD ID CS951480) in blood, unaffected skin, and all tumor samples. In five out of seven analyzed tumors, we additionally detected second-hit mutations in the NF1 gene. Four of them were novel and one was previously observed. Each mutation was distinct, demonstrating the independent origin of each tumor. Only in two of seven tumors we detected an additional somatic mutation that was not associated with NF1. Our study demonstrated that somatic mutations of NF1 are likely the main drivers of cutaneous tumor formation. The study provides evidence for the rareness of single base pair level alterations in the exomes of benign NF1 cutaneous tumors. European Journal of Human Genetics (2015) 23, 870-873; doi:10.1038/ejhg.2014.210; published online 8 October 2014

\section{INTRODUCTION}

Neurofibromatosis type 1(NF1) (MIM\#162200) is a fairly common genetic disease with an incidence of about 1 in 3000. It is caused by inactivating mutations in the NF1 gene, which encodes a large protein with function of GTPase-activating protein specific for Ras. Constitutional mutations in NF1 cause susceptibility to tumorigenesis. Cutaneous neurofibromas are the most commonly appearing tumor type in NF1. They are composed of up to $80 \%$ Schwann cells, with some contribution of nerve cells (axons and axon sheaths), fibroblasts, mast cells, and endothelial cells. ${ }^{1}$ Visible growth of cutaneous neurofibromas starts during puberty and accelerates during pregnancy, suggesting hormonal involvement. ${ }^{2}$ In contrast to plexiform neurofibromas that can transform to malignant peripheral nerve sheath tumors, cutaneous neurofibromas in general are benign tumors. ${ }^{3}$

It is broadly accepted that cancer growth is determined by the mutations that confer growth advantage to the cell clones. In the case of aggressively growing cancers, the overwhelming majority carries hundreds to hundreds of thousands of somatic mutations, which is a result of high mutation rates within tumors. ${ }^{4}$ However, some types of tumors have less somatic mutations-for example, medulloblastomas, testicular germ cell tumors, acute leukemias, and carcinoids. ${ }^{4}$ Only a subgroup of mutations is thought to drive cancer progression, as they affect crucial tumor suppressors and protooncogenes. The overwhelming majority are so-called passenger mutations, which accumulate in the genome but convey no direct selective advantage to the cell.

Patients with classical NF1 show constitutional heterozygous pathogenic mutations in the NF1 gene. Loss of the remaining allele in appropriate progenitor cells triggers tumor formation. This notion is supported by studies in mice, in which optic nerve glioma formation requires biallelic astrocyte $\mathrm{Nf1}$ gene inactivation in the presence of $\mathrm{NfI}$ brain heterozygosity. ${ }^{5}$ However, no gliomas are formed in mice when the Nfl gene is inactivated in astrocytes in the absence of a heterozygous background, indicating the need for cooperation of the $\mathrm{Nfl+1}$ - non-neoplastic cells in the tumor microenvironment. ${ }^{6}$ In contrast, investigation of humans with mosaic NF1 mutations shows that neurofibromas and Café-au-lait macules appear also within a wild-type background. ${ }^{7}$ In addition, other factors such as the time point of biallelic inactivation or the expression of modifier genes seem to influence the formation of neurofibromas. ${ }^{8}$ Although these studies support a 'second-hit' hypothesis to explain the origin of NF1 tumors, they also stress the importance of the permissive tumor microenvironment. ${ }^{9}$ In this context, it is interesting that the rate of

${ }^{1}$ FG Development \& Disease, Max Planck Institute for Molecular Genetics, Berlin, Germany; ${ }^{2}$ Institute for Medical Genetics and Human Genetics, Universitätsmedizin Berlin, Charité Berlin - Campus Virchow, Berlin, Germany; ${ }^{3}$ Computational Molecular Biology, Max Planck Institute for Molecular Genetics, Berlin, Germany; ${ }^{4}$ Institute of Bioorganic Chemistry, Polish Academy of Sciences, Poznan, Poland; ${ }^{5}$ Berlin-Brandenburg Center for Regenerative Therapies (BCRT), Berlin, Germany; ${ }^{6}$ Center for Laser Medicine, Evangelic Elisabeth Clinic, Berlin, Germany; ${ }^{7}$ Department of Maxillofacial Surgery, University Hospital Eppendorf, Hamburg, Germany; ${ }^{8}$ Division of Human Genetics, Medical University Innsbruck, Innsbruck, Austria; 'Institute of Clinical Genetics, Carl Gustav Carus Medical Academy, Technical University, Dresden, Germany

${ }^{*}$ Correspondence: Dr M Kolanczyk, Institute for Medical Genetics and Human Genetics, Universitätsmedizin Berlin, Charité Berlin - Campus Virchow, Augustenburger Platz 1 , 13353 Berlin, Germany. Tel: +49 30450569 143; Fax: +49 30450569 915; E-mail: kolanshy@molgen.mpg.de

Received 14 January 2014; revised 12 July 2014; accepted 27 August 2014; published online 8 October 2014 
tumor formation and the overall number of cutaneous neurofibromas vary considerably from patient to patient. The mechanism underlying the differences of phenotype expressivity remains unknown. Similarly unknown is the exact growth mechanism of benign dermal neurofibromas. Although somatic NF1 inactivation has been demonstrated in various NF1 tumor types including cutaneous neurofibromas, ${ }^{10}$ the presence of alterations in other genes has not been systematically investigated in these tumors. Here we applied whole-exome sequencing to investigate somatic mutation landscape in cutaneous neurofibromas.

\section{RESULTS}

\section{Results of exome filtering and molecular screening}

We have sequenced whole exomes of two control tissues (blood and unaffected skin) and seven dermal neurofibroma tumors. The constitutional NF1 mutation was identified on the basis of its presence in tumors, blood, and nonaffected skin DNA. The mutation, c.3113 $+1 \mathrm{G}>\mathrm{A}$, affected the intronic splice site and has been previously reported (HGMD ID CS951480). The somatic mutations were identified by comparing exomes of the seven tumors and the two control samples. In five of seven analyzed neurofibromas, we detected the following somatic NF1 NM_000267.3 mutations:

Tumor \#1: NF1:exon12:c.1324_1331delATGTTTGG: p.(M442*) (frameshift deletion);

Tumor \#2: NF1:exon23:c.3043delC: p.(L1015Cfs ${ }^{\star} 4$ ) (frameshift deletion);

Tumor \#3: NF1:exon47:c.7096_7101delAACTTT: p.(N2366_ F2367del) (non-frameshift deletion);

Tumor \#4: NF1:exon53:c.7846C > T:p.(R2616*) (HGMD ID M950853) (stopgain);

Tumor \#5: NF1:exon56:c.8112delA: p.(D2705Tfs ${ }^{\star}$ 13) (frameshift deletion);

Tumor \#6 and Tumor \#7: no NF1 somatic mutation was detected. (Abbreviations: del, deletion; fs, frameshift; ${ }^{*}$, stopgain) (for more details see Table 1).

With the exception of somatic NF1 mutation in tumor 3, from which there was no DNA left after exome sequencing, all of the other mutations were confirmed by Sanger sequencing. As denoted above, four of the detected somatic mutations in NF1 were novel and one was previously annotated in the HGMD database. We detected additional somatic mutations outside NF1 in only two of the tumors. These two mutations were confirmed using Sequenom IPlex SNP genotyping service (www.atlas-biolabs.de). The first mutation was present in tumor 2 and was chr1:g.186088422 A>G, which is localized in the HMCN1 gene and results in a nonsynonymous change p.(H3983R). The other mutation variant was in tumor 7, chr17:g.79165131 G>A, and resulted in nonsynonymous change p.(A876V) in the gene AZI1.

\section{MATERIALS AND METHODS}

\section{Materials}

Cutaneous neurofibromas, unaffected skin biopsy sample, and venous blood were obtained from a 53-year-old woman with NF1. A cosmetic cutaneous tumor load reduction surgery was performed with the laser dissection and conventional surgery methods. We collected tumors removed by conventional surgery, which were stored frozen until further preparation. The DNA was extracted from the encapsulated tumors that were cautiously separated from the surrounding connective tissue. Seven geographically distinct tumors from the back and neck, a sample of unaffected skin, and a venous blood sample were used for DNA isolation and sequencing. Written informed consent was obtained from the patient before genetic testing.

\section{Whole-exome sequencing}

Whole-exome sequencing (WES) was done on DNA samples isolated from cutaneous tumors, skin, and blood of a single female of German descent with NF1. DNA was isolated from tissue and blood using Promega Wizard Genomic DNA Purification Kit according to the supplied protocols (Promega, Madison, WI, USA). Each DNA sample was captured using the Agilent SureSelect Human All Exon Kit V2 (Agilent, Santa Clara, CA, USA), and sequencing of $100 \mathrm{bp}$ paired end reads was carried out on Illumina HiSeq 2000 (Illumina, San Diego, CA, USA). Sequence reads were aligned to the haploid human reference genome (hg 19) using Novoalign (Novocraft Technologies, Petaling Jaya, Malaysia). Single-nucleotide variants and short insertions and deletions (indels) were called using SAMtools. ${ }^{11}$ All detected variants were annotated with Annovar. ${ }^{12}$ Good quality of the exome sequencing results was ascertained by the analysis of genotyping accuracy (see Supplementary Figures S1 and S2). Tumor vcf files were first filtered for technical artifacts of sequencing, lowquality data $(\mathrm{Q}<60)$, and then compared against blood and nonaffected skin samples using a set of Perl scripts. Finally, to predict the pathogenic potential of missense variants, we used Mutation Taster. ${ }^{13}$ Variants were visualized with the use of the Integrative Genomics Viewer. ${ }^{14,15}$ Variants were then validated with standard Sanger sequencing or Sequenom IPlex SNP genotyping (www.atlasbiolabs.de).

\section{Reference sequences}

Reference Genome: NCBI37; NF1: NG_009018.1, NM_000267.3, NP_000258.1; HMCN1: NG_011841.1, NM_031935.2, NP_114141.2; AZI1: ENSG00000141577, NM_014984.2, NP_055799.2; Exon numbering like in the transcripts specified above. All variants were submitted to LOVD http:// databases.lovd.nl/shared/genes, Individual ID: \#00016860.

\section{Sanger sequencing}

Sanger sequencing was conducted as described previously. ${ }^{16}$ The presence of second-hit mutations in NF1 was confirmed using the following primer pairs for amplification of the exons of interest:

\begin{tabular}{ll}
\hline NF1_1_MID8_fw & CTCCACAGACCCTCTCCTTG \\
NF1_1_MID8_w & CTTCCCTTCCTTTCCTCCAG \\
NF1_12_MID8_fw & TGGTGTGTGTTTGCATGGTC \\
NF1_12_MID8_rv & ACCAAAGCAGCAGGAATAGG \\
NF1_23_MID8_ww & CCAGAAGTTGTGTACGTTCTTTTCT \\
NF1_23_MID8_rv & CCTTTCTACCAATAACCGCATATC \\
NF1_47_MID8_w & TGTTCTGTGGTTTTCTGCAGTC \\
NF1_47_MID8_rv & AAGGGCTAACTTACTTCAATTTATTTC \\
NF1_53_MID8_fw & TCAGCCACAAAGTAAAAATGTTG \\
NF1_53_MID8_rv & GGTCAAAACTAATCTTAACCCTCA \\
NF1_56_MID8_fw & ATTTTTGGCTTCAGATGGGG \\
NF1_56_MID8_rv & GGGAATTCCTAATGTTGGTGTC \\
\hline
\end{tabular}

\section{Microarray-based comparative genomic hybridization}

All experiments were done with genomic DNA extracted from blood compared with DNA extracted from tumor samples. Array comparitive genome hybridization (array CGH) was carried out using a whole-genome $1 \mathrm{M}$ oligonucleotide array (Agilent). The $1 \mathrm{M}$ arrays were analyzed by Feature Extraction v9.5.3.1 and Cytogenomics v2.7.8.0, respectively (Agilent). Analysis settings: aberration algorithm: ADM-2; threshold: 6.0 ; window size: $0.2 \mathrm{Mb}$; filter: 5 probes, $\log 2$ ratio $=0.29$. The genomic profile was visualized using the Agilent CytoGenomics software (Agilent CytoGenomics v2.7.8.0.).

\section{DISCUSSION}

Consistent with previous reports, we have detected second-hit somatic mutations in the NF1 gene. The NF1 gene was well covered by the exome sequencing, with the exception of exon 1 , which was not covered by the exome probes and was subsequently interrogated using Sanger sequencing. 
Table 1 Germline and somatic variants detected in the blood, skin, and tumors

\begin{tabular}{|c|c|c|c|c|c|c|c|c|c|c|c|}
\hline Sample & Chr. & $\begin{array}{l}\text { NCBI } 37 \\
\text { Position }\end{array}$ & $\begin{array}{l}\text { Gene/ } \\
\text { exon }\end{array}$ & $\begin{array}{c}\text { Ref. } \\
\text { genotype }\end{array}$ & $\begin{array}{c}\text { Mut. } \\
\text { genotype }\end{array}$ & Effect & $\begin{array}{l}\text { HGMD ID/ } \\
\text { LOVD ID }\end{array}$ & Status & $\begin{array}{l}\text { Reads with } \\
\text { reference allele }\end{array}$ & $\begin{array}{l}\text { Reads with } \\
\text { mutant allele }\end{array}$ & $\begin{array}{l}\% \text { of } \\
\text { mutant } \\
\text { allele }\end{array}$ \\
\hline $\begin{array}{l}\text { Skin (internal ID } \\
\text { 274) }\end{array}$ & 17 & 29557401 & $N F 1 / 23$ & G & A & $\begin{array}{l}\text { c. } 3113+1 \mathrm{G}>\mathrm{A} \\
\text { (splicing) }\end{array}$ & $\begin{array}{l}\text { CS951480/ } \\
0000036837\end{array}$ & Germline & $\begin{array}{l}\rightarrow 4 \\
\leftarrow 6\end{array}$ & $\begin{array}{l}\rightarrow 6 \\
\leftarrow 4\end{array}$ & $50 \%$ \\
\hline & 17 & 29557401 & $N F 1 / 23$ & G & A & $\begin{array}{l}\text { c. } 3113+1 G>A \\
\text { (splicing) }\end{array}$ & $\begin{array}{l}\text { CS951480/ } \\
0000036837\end{array}$ & Germline & $\begin{array}{l}\rightarrow 23 \\
\leftarrow 26\end{array}$ & $\begin{array}{l}\rightarrow 12 \\
\leftarrow 26\end{array}$ & $43 \%$ \\
\hline \multirow[t]{2}{*}{$\begin{array}{l}\text { Tumor2 } \\
\text { (internal ID 272) }\end{array}$} & 17 & 29557330 & $N F 1 / 23$ & C & - & $\begin{array}{l}\text { p.(L1015Cfs*4) (frame- } \\
\text { shift-deletion) }\end{array}$ & 0000036839 & Somatic & $\begin{array}{l}\rightarrow 12 \\
\leftarrow 12\end{array}$ & $\begin{array}{l}\rightarrow 4 \\
\leftarrow 3\end{array}$ & $22 \%$ \\
\hline & 17 & 29557401 & $N F 1 / 23$ & G & A & $\begin{array}{l}\text { c. } 3113+1 G>A \\
\text { (splicing) }\end{array}$ & $\begin{array}{l}\text { CS951480/ } \\
0000036837\end{array}$ & Germline & $\begin{array}{l}\rightarrow 10 \\
\leftarrow 7\end{array}$ & $\begin{array}{l}\rightarrow 7 \\
\leftarrow 7\end{array}$ & $45 \%$ \\
\hline & 17 & 29557401 & $N F 1 / 23$ & G & A & $\begin{array}{l}\text { c. } 3113+1 \mathrm{G}>\mathrm{A} \\
\text { (splicing) }\end{array}$ & $\begin{array}{l}\text { CS951480/ } \\
0000036837\end{array}$ & Germline & $\begin{array}{l}\rightarrow 12 \\
\leftarrow 11\end{array}$ & $\begin{array}{l}\rightarrow 7 \\
\leftarrow 20\end{array}$ & $54 \%$ \\
\hline \multirow[t]{2}{*}{$\begin{array}{l}\text { Tumor4 } \\
\text { (internal ID 477) }\end{array}$} & 17 & 29684326 & $N F 1 / 53$ & C & T & $\begin{array}{l}\text { p.(R2616*) } \\
\text { (stopgain) }\end{array}$ & $\begin{array}{l}\text { CM950853/ } \\
0000036841\end{array}$ & Somatic & $\begin{array}{l}\rightarrow 34 \\
\leftarrow 29\end{array}$ & $\begin{array}{l}\rightarrow 7 \\
\leftarrow 5\end{array}$ & $16 \%$ \\
\hline & 17 & 29557401 & $N F 1 / 23$ & G & $A$ & $\begin{array}{l}\text { c. } 3113+1 \mathrm{G}>\mathrm{A} \\
\text { (splicing) }\end{array}$ & $\begin{array}{l}\text { CS951480/ } \\
0000036837\end{array}$ & Germline & $\begin{array}{l}\rightarrow 14 \\
\leftarrow 17\end{array}$ & $\begin{array}{l}\rightarrow 8 \\
\leftarrow 16\end{array}$ & $43 \%$ \\
\hline \multirow[t]{2}{*}{$\begin{array}{l}\text { Tumor5 } \\
\text { (internal ID 271) }\end{array}$} & 17 & 29687519 & $N F 1 / 56$ & A & - & $\begin{array}{l}\text { p.(D2705Tfs*13) } \\
\text { (frameshift-deletion) }\end{array}$ & 0000036842 & Somatic & $\begin{array}{l}\rightarrow 51 \\
\leftarrow 19\end{array}$ & $\begin{array}{l}\rightarrow 25 \\
\leftarrow 2\end{array}$ & $27 \%$ \\
\hline & 17 & 29557401 & $N F 1 / 23$ & G & $A$ & $\begin{array}{l}\text { c. } 3113+1 \mathrm{G}>\mathrm{A} \\
\text { (splicing) }\end{array}$ & $\begin{array}{l}\text { CS951480/ } \\
0000036837\end{array}$ & Germline & $\begin{array}{l}\rightarrow 4 \\
\leftarrow 16\end{array}$ & $\begin{array}{l}\rightarrow 8 \\
\leftarrow 11\end{array}$ & $48 \%$ \\
\hline $\begin{array}{l}\text { Tumor6 } \\
\text { (internal ID 273) } \\
\text { Tumor7 } \\
\text { (internal ID 475) }\end{array}$ & 17 & 29557401 & $N F 1 / 23$ & G & A & $\begin{array}{l}\text { c. } 3113+1 \mathrm{G}>\mathrm{A} \\
\text { (splicing) }\end{array}$ & $\begin{array}{l}\text { CS951480/ } \\
0000036837\end{array}$ & Germline & $\begin{array}{l}\rightarrow 6 \\
\leftarrow 2\end{array}$ & $\begin{array}{l}\rightarrow 3 \\
\leftarrow 3\end{array}$ & $42 \%$ \\
\hline
\end{tabular}

Abbreviations: Chr, chromosome; Mut, mutated; Ref, reference.

NF1 mutations in seven whole-exome-sequenced NF1 cutaneous neurofibroma tumors and control tissues are shown in the table. The table indicates genomic position (NCBI 37/Ensembl 66),

reference sequence, altered sequence, and the type of protein alteration caused. Note that germline mutation c.3113+1G $>$ A was detected in all analyzed samples. No somatic NF1 mutations were detected in tumors 6 and 7 . The columns 'reads reference' and 'reads mutant' give the number of reads covering reference and mutant allele (in both directions) in the original BAM file (DP4).

We detected somatic inactivating events in five out of seven analyzed tumors. All variants are single-nucleotide exchanges or small deletions. This is line with the work of Thomas et all ${ }^{17}$ who found similar types of variants in most neurofibromas. It is plausible that in two tumors in which we did not detect single-nucleotide-level mutation, other genetic events took place, for example, deletion or mutation in the regulatory NF1 sequences. However, high-resolution array CGH analysis did not reveal any copy number changes in the tumor samples. In the tumor samples in which we detected somatic NF1 variants, the percentage of reads with de novo-altered NF1 nucleotide sequence within all reads was in the range of $16-27 \%$ (Table 1). Thus, the coverage was sufficient to detect second-hit mutations in NF1 and should therefore also be sufficient to detect variants in other genes. Indeed, in addition to somatic variants in NF1 gene, we selected several candidate somatic variants in other genes that were all supported by the low number of reads. Existence of only two of these additional somatic variants (tumor 2 - chr1:g.186088422 A> G; tumor 7 - chr17:g.79165131 $\mathrm{G}>\mathrm{A}$ ) could be confirmed using Sequenom IPlex SNP genotyping service. The first variant introduced a benign p.(H3983R) change in the $\mathrm{HMCN} 1$ protein, which recapitulates mouse HMCN1 protein sequence and is therefore unlikely of significance. The second variant introduced a change at the conserved position p.(A876V) in AZI1 (Azacytidine-induced 1), which is a protein involved in the regulation of genome stability. ${ }^{18}$ This variant is potentially deleterious to protein function (Mutation taster prediction: disease causing); however, currently there are no published data that would directly implicate AZI1 gene in tumorigenesis.

Collectively, our results suggest that somatic mutation rate in cutaneous neurofibromas is low. The identified second-hit mutations in NF1 were randomly distributed within the gene, and four of them were novel (not previously annotated in the HGMD database). All NF1 variants found in this study were predicted to either truncate or be deleterious to the protein function using Mutation Taster algorithm. These data suggest that second-hit mutations in NF1 are likely sufficient to induce the growth of cutaneous neurofibromas. Interestingly, similar findings were made in the recent wholegenome sequencing study of low-grade brain tumors (pilocytic astrocytomas). ${ }^{19}$ In this study, only one somatic NF1 mutation was detected in three tumors and only few additional nonrecurrent, nonprotein sequences affecting mutations were found. The study 
concluded that mutation frequency in NF1 pilocytic astrocytoma is relatively low, which is similar to that of other pediatric solid tumors where carcinogenesis often results from antecedent germline mutations. Our current study reaffirms this notion in the context of the most frequent of the NF1 tumor types, the NF1 dermal neurofibroma. Thus, a single event of second-hit mutation in NF1 gene is likely sufficient for the formation of the benign cutaneous neurofibromas.

\section{CONFLICT OF INTEREST}

The authors declare no conflict of interest.

\section{ACKNOWLEDGEMENTS}

We are grateful to the NF1 patient for participating in this study. This study was supported by the Bundesministerium für Bildung und Forschung (BMBF), Grant NF1-01GM0844. Patient consent was obtained. Ethics approval was granted by the Institutional Review Board.

1 Friedrich RE, Holstein AF, Middendorff R, Davidoff MS. Vascular wall cells contribute to tumorigenesis in cutaneous neurofibromas of patients with neurofibromatosis type 1 . A comparative histological, ultrastructural and immunohistochemical study. Anticancer Res 2012; 32: 2139-2158.

2 Roth TM, Ramamurthy P, Muir D et al: Influence of hormones and hormone metabolites on the growth of Schwann cells derived from embryonic stem cells and on tumor cell lines expressing variable levels of neurofibromin. Dev Dyn 2008; 237: 513-524.

3 Ferner RE, Gutmann DH. International consensus statement on malignant peripheral nerve sheath tumors in neurofibromatosis. Cancer Res 2002; 62: 1573-1577.

4 Vogelstein B, Papadopoulos N, Velculescu VE, Zhou S, Diaz Jr LA, Kinzler KW. Cancer genome landscapes. Science 2013; 339: 1546-1558.
5 Bajenaru ML, Hernandez MR, Perry A et al: Optic nerve glioma in mice requires astrocyte Nf1 gene inactivation and Nf1 brain heterozygosity. Cancer Res 2003; 63 : 8573-8577.

6 Bajenaru ML, Zhu Y, Hedrick NM, Donahoe J, Parada LF, Gutmann DH. Astrocytespecific inactivation of the neurofibromatosis 1 gene (NF1) is insufficient for astrocytoma formation. $\mathrm{Mol}$ Cell Biol 2002; 22: 5100-5113.

7 Maertens O, De Schepper S, Vandesompele J et al: Molecular dissection of isolated disease features in mosaic neurofibromatosis type1. Am J Hum Genet 2007; 81: 243-251.

8 Carroll SL, Ratner N. How does the Schwann cell lineage form tumors in NF1? Glia 2008; 56: 1590-1605.

9 Le LQ, Shipman T, Burns DK, Parada LF. Cell of origin and microenvironment contribution for NF1-associated dermal neurofibromas. Cell Stem Cell 2009; 4: 453-463.

10 Laycock-van Spyk S, Thomas N, Cooper DN, Upadhyaya M. Neurofibromatosis type 1-associated tumors: their somatic mutational spectrum and pathogenesis. Hum Genomics 2011; 5: 623-690.

$11 \mathrm{Li} \mathrm{H}$, Durbin R. Fast and accurate short read alignment with Burrows-Wheeler transform. Bioinformatics 2009; 25: 1754-1760.

12 Wang K, Li M, Hakonarson H. ANNOVAR: functional annotation of genetic variants from high-throughput sequencing data. Nucleic Acids Res 2010; 38: e164.

13 Schwarz JM, Rodelsperger C, Schuelke M, Seelow D. MutationTaster evaluates diseasecausing potential of sequence alterations. Nat Methods 2010; 7: 575-576.

14 Thorvaldsdóttir H, Robinson JT, Mesirov JP. Integrative Genomics Viewer (IGV): highperformance genomics data visualization and exploration. Brief Bioinform 2013; 14: 178-192.

15 Robinson JT, Thorvaldsdóttir H, Winckler $\mathrm{W}$ et al: Integrative genomics viewer. Nat Biotechnol 2011; 29: 24-26.

16 Baasanjav S, Jamsheer A, Kolanczyk M et al: Osteopoikilosis and multiple exostoses caused by novel mutations in LEMD3 and EXT1 genes respectively-coincidence within one family. BMC Med Genet 2010; 11: 110.

17 Thomas L, Spurlock G, Eudall C et al: Exploring the somatic NF1 mutational spectrum associated with NF1 cutaneous neurofibromas. Eur J Hum Genet 2012; 20: 411-419.

18 Staples CJ, Myers KN, Beveridge RD et al: The centriolar satellite protein Cep131 is important for genome stability. J Cell Sci 2012; 125: 4770-4779.

19 Gutmann DH, McLellan MD, Hussain I et al: Somatic neurofibromatosis type 1 (NF1) inactivation characterizes NF1-associated pilocytic astrocytoma. Genome Res 2013; 23: $431-439$

Supplementary Information accompanies this paper on European Journal of Human Genetics website (http://www.nature.com/ejhg) 